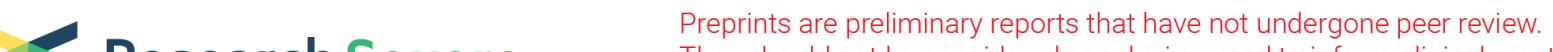 Research Square
Thr ef should not be considered conclusive, used to inform clinical practice,
on the media as validated information.
}

\section{Effect of Sanguisorba Minor on Scopolamine- induced Memory Loss in Rat: Involvement of Oxidative Stress and Acetylcholinesterase}

\section{Zeinab Hosseini}

Mashhad University of Medical Sciences

Fatemeh Mansouritorghabeh

Mashhad University of Medical Sciences

Faezeh Sadat Hosseini Kakhki

Massachusetts General Hospital

Mahmoud Hosseini

Mashhad University of Medical Sciences Faculty of Medicine

Hassan Rakhshandeh

Mashhad University of Medical Sciences

Azar Hosseini

Mashhad University of Medical Sciences

Maede Hasanpour

Mashhad University of Medical Sciences

Mehrdad Iranshahi

Mashhad University of Medical Sciences Faculty of Pharmacy

Arezoo Rajabian ( $\square$ rajabianar@mums.ac.ir)

Mashhad University of Medical Sciences Emam Reza Hospital https://orcid.org/0000-0003-3765-7463

\section{Research Article}

Keywords: Acetyl cholinesterase, Cognitive decline, Oxidative injury, Sanguisorba minor, Scopolamine

Posted Date: June 30th, 2021

DOl: https://doi.org/10.21203/rs.3.rs-599059/v1

License: (c) (1) This work is licensed under a Creative Commons Attribution 4.0 International License. Read Full License

Version of Record: A version of this preprint was published at Metabolic Brain Disease on January 4th, 2022. See the published version at https://doi.org/10.1007/s11011-021-00898-y. 


\section{Abstract}

Sanguisorba minor (S. minor) has neuroprotective and antioxidant activities; nevertheless, its potential benefits in ameliorating learning and memory functions have not been explored yet. So, in this study, rats were treated with $S$. minor hydro-ethanolic extract $(50,100$, and $200 \mathrm{mg} / \mathrm{kg}$, intraperitoneal (i.p.)) as well as rivastigmine $(0.5 \mathrm{mg} / \mathrm{kg}$, i.p.) for 21 consecutive days. Thereafter, their behavioral performance was assessed using Morris water maze (MWM) and passive avoidance (PA) tasks. Scopolamine was also injected 30 min before conducting the tasks. Finally, oxidative stress biomarkers and acetyl cholinesterase (AChE) activity were determined in the brain. The extract characterization was presented using liquid chromatography-mass spectrometry (LC-MS), which confirmed the presence of quercetin, myricetin, kaempferol, catechin, ellagic acid, and gallic acid derivatives. According to the results, the extract at all doses could significantly recover the impairment of cognitive performance of the scopolamine-treated rats. In the MWM test, the extract and rivastigmine reduced escape latency and travelled distance, compared to the scopolamine group. Moreover, in the PA test, the latency to enter the dark chamber was significantly increased by the extract and rivastigmine, compared to the scopolamine group ( $p<0.05-p<0.001)$. Similar to rivastigmine, the extract attenuated both AChE activity and oxidative injury in the brain as evidenced by the increased antioxidant enzymes and total thiol content, but it decreased malondialdehyde level $(p<0.05-p<0.001)$. In conclusion, the results suggested the effectiveness of $S$. minor on preventing cognitive dysfunction induced by scopolamine. Accordingly, these protective effects might be produced through the regulation of cholinergic activity and oxidative stress.

\section{Introduction}

Dementia and neurodegenerative diseases are accompanied with cognitive impairments (Terry et al. 2011). Functional deficits in cholinergic neurotransmission have been found to be directly linked to cognitive impairments. Hence, many studies have recently focused on the cholinergic system (Parfitt et al. 2012; Giovannini et al. 2015). The function of acetyl choline (ACh), a major neurotransmitter in the central cholinergic system, is important in the process of perception, attention, learning, and memory. ACh function in the hippocampus and brain cortex is terminated by acetyl cholinesterase (AChE) (Hasselmo 2006).

Acetyl cholinesterase inhibitors (AChEls), including rivastigmine, galantamine, and donepezil, are currently used as the most effective pharmacotherapeutic agents. Correspondingly, these can ameliorate cognitive deficits through the activation of the central cholinergic system (El-Marasy et al. 2012). However, alternative or adjuvant anti-amnestic therapies are required in this regard because these drugs produce some adverse effects ( $\mathrm{Ng}$ et al. 2006).

The roles of oxidative stress and cholinergic dysfunction in cognitive decline have been explored in some studies (Li et al. 2018). Scopolamine, as a muscarinic cholinergic receptor antagonist, was observed to impair short-term memory and learning ability (Klinkenberg and Blokland 2010). As well, the induction of 
AChE activity by scopolamine contributes to mitochondria dysfunction and subsequently to oxidative stress (Melo et al. 2003; Leuner et al. 2012).

Sanguisorba minor (S. minor) is a member of the Rosaceae family that has been traditionally used for the treatment of some diseases such as bleeding, eczema, and diarrhea (Zhao et al. 2017). A variety of biological activities, including anti-inflammatory, antibacterial, antiviral, anti-oxidant, neuroprotective, and anticancer effects were proposed for $S$. minor extracts (Zhao et al. 2017; Cirovic et al. 2020; Finimundy et al. 2020). The ethanol extract of $S$. minor could also suppress cyclooxygenase- 1 and AChE enzymes activity in vitro (Cirovic et al. 2020; Finimundy et al. 2020). Additionally, some in vitro protective properties of $S$. minor against $\beta$-amyloid neurotoxicity were found (Nguyen et al. 2008; Akbari et al. 2019; Ferreira et al. 2006; Soodi et al. 2017). However, memory-enhancing activity of $S$. minor has been assessed in no studies so far. Thus, the present study aimed to examine the anti-amnestic potential of $S$. minor in the rats with scopolamine-induced memory loss.

\section{Material And Methods}

\section{Preparation of S. minor hydro-ethanolic extract}

S. minor was collected from Ghoochan region (Khorasan Razavi province, Iran), which was then identified by a botanist (M.R. Joharchi) at Ferdowsi University, Mashhad, Iran (herbarium No. 45489). Thereafter, the aerial parts of the plant were shade-dried, crushed to a fine powder $(50 \mathrm{~g})$, and then soaked in $200 \mathrm{ml}$ of a hydro-ethanolic solution $(50 \%, v / v)$ for $48 \mathrm{~h}$ at $40^{\circ} \mathrm{C}$. Finally, the hydro-alcoholic extract was filtered and then concentrated using a rotary vacuum evaporator at $37^{\circ} \mathrm{C}$ (Norouzi et al., 2019; Rajabian et al., 2016).

\section{Liquid chromatography-mass spectrometry (LC-MS) apparatus}

The LC-MS analysis was performed in an AB SCIEX QTRAP (Shimadzu) liquid chromatography coupled with a triple-quadrupole mass spectrometer. MS analysis was conducted in both negative and positive modes of ionization, in order to maximize the number of the monitored metabolites ions. Liquid chromatography was performed on a Supelco C18 $(15 \mathrm{~mm} \times 2.1 \mathrm{~mm} \times 3 \mu \mathrm{m})$ column at a flow-rate of 0.7 $\mathrm{ml} / \mathrm{min}$. The gradient analysis started with $90 \%$ of $0.1 \%$ aqueous formic acid, isocratic conditions were maintained for $15 \mathrm{~min}$, and then a 20 -min linear gradient to $30 \%$ methnol along with $0.1 \%$ formic acid was applied. From the time of $35 \mathrm{~min}$ to $80 \mathrm{~min}$, the acidified methanol was increased to $100 \%$, followed by $10 \mathrm{~min}$ of $100 \%$ acidified methanol, and finally $10 \mathrm{~min}$ of $90 \%$ of aqueous formic acid to re-equilibrate the column. Finally, the mass spectra were acquired in a range of 200 to 1200 after the 100 -minute scan time. Mass feature's extraction of the acquired LC-MS data and the maximum detection of peaks were done using MZmine analysis software package, version 2.3.

\section{Chemicals}


For performing this study, 5,5'-Dithiobis-2-nitrobenzoic acid (DTNB), 2-thiobarbituric acid (TBA), hydrochloric acid $(\mathrm{HCl})$, trichloroacetic acid (TCA), ethylenediamine tetra acetic acid disodium salt (Na2EDTA), tris (hydroxymethyl) aminomethane (Trizma base), phosphate buffered saline (PBS), and dimethyl sulfoxide (DMSO) were purchased from Merck (Darmstadt, Germany). As well, scopolamine and acetylthiocholine iodide were purchased from Sigma (St. Louis, USA). Notably, rivastigmine was kindly provided by Hakim Company (Tehran, Iran).

\section{Animals}

Male Wistar rats (aged 6-8 weeks, weighted $200 \pm 20 \mathrm{~g}$ ) were obtained from the animal house of the Faculty of Medicine, Mashhad University of Medical Sciences, Mashhad, Iran. The needed experimental procedures were performed in compliance with the National Institutes of Health Guidance for the Care and Use of Laboratory Animals. Additionally, the Animal Ethics Committee of the Mashhad University of Medical Sciences approved the experimental protocols of this study (IR.MUMS.MEDICAL.REC.1398.655). The animals were housed under the standard conditions (at $22 \pm 2^{\circ} \mathrm{C}, 12 \mathrm{~h}$ light-dark cycles: light on from 7:00 to 19:00), with free access to food and water ad libitum.

\section{Drug administration and experimental design}

After the acclimatization for 1 week, the rats were randomly allocated into the following five groups ( $\mathrm{n}=$ 10 per group): Control group (group I) received saline (intraperitoneal (i.p.) injection, $1 \mathrm{~mL} / \mathrm{kg}$, daily); scopolamine group (group II) received saline (i.p.) for two weeks and then the treatment with scopolamine was performed ( $2 \mathrm{mg} / \mathrm{kg}$ dissolved in saline, i.p.) (Ghasemi et al. 2019; Marefati et al. 2019; Lee et al. 2015; Sun et al. 2019; Deb et al. 2015) 30 min before conducting the behavioral tests (Brinza et al. 2021; Hoang et al. 2020; Marefati et al. 2019; Ghasemi et al. 2019); and the treatment groups III-VI received 50,100 , and $150 \mathrm{mg} / \mathrm{kg}$ of $S$. minor extract (i.p.) or rivastigmine $(0.5 \mathrm{mg} / \mathrm{kg}$, i.p.) as the standard drug for a two-week period. Accordingly, during these two weeks, scopolamine was not injected. In the third week, the extract or rivastigmine was administered (i.p.) 30 min before administrating scopolamine (i.p.). In groups II- $\mathrm{VI}$, a single dose of scopolamine was administered $30 \mathrm{~min}$ before conducting each trial in the behavioral tests (Ghasemi et al. 2019; Marefati et al. 2019; Brinza et al. 2021; Hoang et al. 2020).

\section{Behavioral assessments}

Morris water maze (MWM) test

Spatial learning and memory were examined using MWM task (Morris 1984), which is a black circular tank $\left(136 \mathrm{~cm}\right.$ in diameter and $60 \mathrm{~cm}$ in height) containing water (depth of $30 \mathrm{~cm}$, at $24 \pm 1^{\circ} \mathrm{C}$ ). A circular platform (10 cm in diameter) was set $2 \mathrm{~cm}$ under the surface of the water in the center of the southwest quadrant of the pool. Swimming behaviors were recorded by a camera that was connected to a computer and the parameters, including latency to find the hidden platform and traveled distance were calculated. At the first day of performing the MWM test, each one of the rats was acclimatized to the maze for $30 \mathrm{sec}$ in the absence of the platform. At each one of the 4-day training period, 4 trials was performed for each animal. For each trial, the rat was separately placed (facing the wall) into each one of four starting points 
(North (N), East (E), South (S), and West (W)) and then, it was practiced to find the platform within 60 sec. If the rat found the platform, it was allowed to stay there for $15 \mathrm{sec}$, otherwise, it was then guided to the platform gently. After each trial, the rat was transferred to its cage and allowed to be dried. By passing 24 hours from the acquisition phase, spatial probe test was performed while removing the platform from the pool and the rat was allowed to seek out the platform in $60 \mathrm{sec}$ (Norouzi et al. 2019).

Passive avoidance (PA) test

A passive avoidance (PA) learning test was performed to evaluate memory retention (Norouzi et al. 2019). The apparatus used for PA test was an acrylic shuttle box consisting of a white illuminated compartment and a dark one $(30 \mathrm{~cm} \times 20 \mathrm{~cm} \times 20 \mathrm{~cm})$ that were connected to each other via a guillotine door. In a habituation session, the rats were individually put into the light chamber and then allowed to move freely between the two chambers for 5 min. For performing the acquisition trial, an inescapable foot-shock ( 2 $\mathrm{mA}$ for $2 \mathrm{sec}$ ) was delivered to the animals through the grid floor by passing $5 \mathrm{sec}$ from entering the dark compartment. The retention trials were done $3 \mathrm{~h}, 24,48 \mathrm{~h}$, and $72 \mathrm{~h}$ later. In these trails, the rats were placed in the light chamber and an entering delay of the rat to the dark chamber was then measured as the latency time. Additionally, the time spent by the animal in the dark and light compartments was recorded (Bavarsad et al. 2020). Notably, in retention trails, the shock punishment was not applied.

\section{Biochemical measurements}

Tissue preparation

Following conducting the behavioral assessments, the rats were euthanized under deep anesthesia (using i.p. injection of ketamine and xylazine at $100 \mathrm{mg} / \mathrm{kg}$ and $15 \mathrm{mg} / \mathrm{kg}$, respectively) and the wholebrain tissues were quickly isolated afterward. A tissue homogenate of cerebral cortex and hippocampus $\left(10 \% \mathrm{w} / \mathrm{v}\right.$ ) was prepared in ice-cold $0.1 \mathrm{M}$ PBS (with pH level of 7.4 ), which was then stored at $-80^{\circ} \mathrm{C}$ for biochemical assessments (Norouzi et al. 2019).

\section{Measurement of oxidative stress biomarkers}

Assay of lipid peroxidation

Lipid peroxidation was measured on the basis of formation of thiobarbituric acid reactive substances (TBARS) following MDA reaction with TBA (Norouzi et al. 2019). In this regard, MDA was regarded as the main product of lipid peroxidation and TBARS (red color) was then expressed as MDA equivalent. In brief, the reaction mixture was prepared by adding TBA/TCA/HCl reagent $(2 \mathrm{~mL})$ to the homogenates $(1 \mathrm{~mL})$. Subsequently, the obtained mixture was heated in boiling water and after $40 \mathrm{~min}$, the samples were cooled and the absorbance was spectrophotometrically measured at $412 \mathrm{~nm}$. The following equation was used to calculate the concentration of MDA (Bavarsad et al. 2020).

Concentration $(M)=$ Absorbance $/ 1.56 \times 10^{5}$.

Assessment of total thiol content 
Estimation of total thiol content was done based on the reaction of the thiol groups with DTNB. Firstly, the homogenates were centrifuged at $4^{\circ} \mathrm{C}$ and $1000 \times \mathrm{g}$, and the supernatants were also collected.

Thereafter, Tris-EDTA buffer ( $1 \mathrm{ml}, \mathrm{pH}$ 8.6) was mixed with the supernatant obtained from each sample $(50 \mathrm{ml})$ and the absorbance was then recorded at $240 \mathrm{~nm}$ using a UV-vis spectrophotometer (A1). After adding the DTNB solution ( $20 \mu \mathrm{l}, 10 \mathrm{mM}$ in methanol) to each sample, the absorbance was recorded again (A2). The following equation was used to calculate the total thiol concentration (Bavarsad et al. 2020):

Concentration $(\mathrm{mM})=(\mathrm{A} 2-\mathrm{A} 1-\mathrm{B}) \times 1.07 / 0.05 \times 13.6$.

Where $B$ is the absorbance of the blank.

Assessment of antioxidant enzymes activity

Superoxide dismutase (SOD) activity in the homogenates was assessed using the previously described procedure (M). The amount of SOD inhibiting $50 \%$ of pyrogallol auto-oxidation was defined as one enzyme unit (Bavarsad et al. 2020).

The estimation of catalase (CAT) activity was also done based on its ability in converting hydrogen peroxide to water. The absorbance was read at $240 \mathrm{~nm}$ using the UV-vis spectrophotometer. In this method, the amount of hydrogen peroxide consumed per each milligram of the protein sample was considered as one unit of CAT activity. Finally, the obtained results were shown as unit per gram of tissue (Norouzi et al. 2019).

Assessment of AChE activity

The AChE activity was assessed using the method of Ellman (Ellman et al. 1961). The supernatant obtained from tissue homogenate $(40 \mu \mathrm{l})$ was added to a solution containing PBS $(2.55 \mathrm{ml})$ and DTNB 10 $\mathrm{mM}(0.1 \mathrm{ml})$. The absorbance of the resultant mixture was determined after the incubation for $5 \mathrm{~min}$ at $37^{\circ} \mathrm{C}$. Then, the reaction mixture was further incubated (for $5 \mathrm{~min}$ at $37^{\circ} \mathrm{C}$ ) after adding $0.02 \mathrm{ml}$ of acetylthiocholine. The absorbance of the sample was spectrophotometrically recorded at $412 \mathrm{~nm}$ and AChE activity was estimated as $\mu \mathrm{mol} / \mathrm{g}$ tissue/min.

\section{Statistical analysis}

All the obtained results were presented as mean \pm SEM (standard error of mean) and then analyzed by GraphPad Prism software 8.0 (GraphPad Software, La Jolla, CA, USA). P $<0.05$ was considered as statistically significant. For the data of the acquisition part of the MWM, including the time and distance during the 4 days, the experimental design included treatment and day as a repeated measures. Therefore, two-way analysis of the variance (ANOVA) with repeated measures was used, and interactions were also reported (treatment $x$ day). The remained data were analyzed using one-way ANOVA followed by Tukey's post hoc multiple comparison test. 


\section{Results}

\section{LC-MS analysis of S. minor hydro-ethanolic extract}

In total, 26 compounds were identified in the hydro-ethanolic extract of $S$. minorusing LC-MS analysis in its negative mode. These compounds were phenolic compounds, including quercetin, myricetin, kaempferol, kaempferol-3-glucuronide, quercetin - 3-glucuronide ellagic acid, catechin, and various gallic acid derivatives (consisting of galloyl glucoside, galloylquinic acid, methylgallate hexoside, and catechin gallate). Moreover, Ayoub (2003) isolated unique phenolic carboxylic acids, 4, 8-dimethoxy-7-hydroxy-2oxo-2H-1-benzopyran-5,6-dicarboxylic acid, and 2-(4-carboxy-3-methoxystyryl)-2-methoxysuccinic acid in relatively high amounts in the hydro-ethanolic extract of $S$. minor. This extract also contained a high level of glucogallin, which is a phenolic compound formed from $\beta$-D-glucose and gallic acid. The compounds identified in the extract characterization are shown in Table 1 and total ion chromatograms obtained in ESI- mode are also shown in Fig. 1. The MS spectral data were compared with those that were available in the literature. Figures 1 indicates the examples of ion chromatograms from the total ion chromatogram and the related mass.

\section{S. minor improved memory impairment induced by scopolamine}

\section{MWM test}

Figures $2 a$ and $b$ illustrate the time spent and the distance traveled to reach the platform during the fourday training trials, respectively. The results showed that both the treatment and day affected the time during the 4-day period of learning $\left(F_{(5,936)}=64.11 ; p<0.001\right.$ for the treatment and $F_{(3,936)}=63.49 ; p<$ 0.001 for the day). As well, an interaction was found between the treatment and the day $\left(F_{(15,936)}=2.84\right.$; $p<0.001)$.

The results also show that both the treatment and day affected the distance during the 4-day period of learning $\left(F_{(5,936)}=167.09 ; p<0.001\right.$ for the treatment and $F_{(3,936)}=25.87 ; P<0.001$ for the day $)$. As well, an interaction was found between the treatment and the day $\left(F_{(15,936)}=3.07, p<0.001\right)$. Correspondingly, escape latency time and traveled path were observed to be longer in the scopolamine-injected animals compared to the control group $(p<0.01-p<0.001)$. However, the animals treated with both 50 and 100 $\mathrm{mg} / \mathrm{kg}$ of the extract at the first day showed shorter latency time compared to the scopolamine group ( $\mathrm{p}<$ $0.05-p<0.001)$. Notably, no significant difference was found in terms of the latency time between the 200 $\mathrm{mg} / \mathrm{kg}$ extract group or rivastigmine-treated group and the scopolamine group at the first day. Besides, the treatment with the extract (at all doses) and rivastigmine significantly reduced the escape latency time compared to that of the scopolamine group, on days $2-4(p<0.001)$. Additionally, it was observed that the administration of the extract (at all doses) and rivastigmine significantly decreased the traveled path compared to that of the scopolamine group $(p<0.001)$. Therefore, it can be stated that the treatment with rivastigmine and the extract significantly improved memory performance compared to the scopolamine group $(p<0.001)$. 
According to the results of the probe test (Figs. $3 a$ and b), both the time spent and the distance traveled in the target quadrant significantly decreased in the scopolamine group compared to the control group $(\mathrm{p}<$ 0.001). Moreover, the animals treated with rivastigmine and the extract (at all doses) exhibited longer time spent and distance traveled in the target quadrant than those of the scopolamine group $(p<0.001)$. Some significant differences were also found in terms of the time spent in the quadrant between the groups treated with 50 and $100 \mathrm{mg} / \mathrm{kg}$ of the extract as well as between the groups treated with 100 and $200 \mathrm{mg} / \mathrm{kg}$ of the extract $(p<0.001)$. Similarly, a significant difference was found in terms of the distance traveled in the quadrant between the two groups treated with 50 and $100 \mathrm{mg} / \mathrm{kg}$ of the extract $(p<0.001)$.

\section{Passive avoidance test}

As illustrated in Figs. $4 a$ and b, in comparison to the control group, the scopolamine-injected animals exhibited lower time latency to enter the dark chamber 3,24 , and $48 \mathrm{~h}$ after the shock $(p<0.01, p<0.001)$. Besides, no significant difference was observed in terms of the time latency $72 \mathrm{~h}$ after the shock between the scopolamine group and the control group.

In contrast, higher time latencies were observed $3,24,48$, and $72 \mathrm{~h}$ after the shock in those rats that were treated with rivastigmine compared to the rats in the scopolamine group $(p<0.05, p<0.001)$. Moreover, the administration of the extract at both 100 and $200 \mathrm{mg} / \mathrm{kg}$ was found to be associated with a significant increase in the time latency $3,24,48$, and $72 \mathrm{~h}$ after the shock compared to the scopolamine group ( $p<0.001)$. As well, some significant differences were observed in the time latency $3,24,48$, and $72 \mathrm{~h}$ after the shock between the two groups treated with 50 and $100 \mathrm{mg} / \mathrm{kg}$ of the extract as well as between the two groups treated with 50 and $200 \mathrm{mg} / \mathrm{kg}$ of the extract $(p<0.001)$.

On other hand, the animals in the scopolamine group were observed to spend longer times in the dark chamber than the control group at 3,24 , and $48 \mathrm{~h}$ time points $(p<0.001)$. However, no significant differences were observed in this regard between the scopolamine and control groups $72 \mathrm{~h}$ after the shock. Besides, the animals treated with rivastigmine were found to spend shorter times in the dark compartment $3,24,48$, and $72 \mathrm{~h}$ after the shock compared to the scopolamine group $(\mathrm{p}<0.01,0.001)$. Furthermore, the administration of the extract (at all doses) caused a significant increase in the time spent in the dark at $3,24,48$, and $72 \mathrm{~h}$ after the shock compared to the scopolamine group ( $p<0.05$ to $p$ $<0.001)$. Moreover, the animals treated with the extract $(50 \mathrm{mg} / \mathrm{kg}$ ) indicated no significant difference in the time spent in the dark, $48 \mathrm{~h}$ after the shock compared to the scopolamine group. However, some significant differences were reported in the time spent in the dark $3,24,48$, and $72 \mathrm{~h}$ after the shock between the two groups treated with 50 and $100 \mathrm{mg} / \mathrm{kg}$ of the extract as well as between the two groups treated with 100 and $200 \mathrm{mg} / \mathrm{kg}$ of the extract $(\mathrm{p}<0.001)$.

As illustrated in Fig. 4c, the time spent in the light chamber significantly decreased following the injection of scopolamine $(p<0.001)$ in comparison to the control group 3,24 , and $48 \mathrm{~h}$ after the shock $(p<0.001)$. However, no significant difference was observed in this regard between the scopolamine and the control groups $72 \mathrm{~h}$ after the shock. However, a longer time was spent in the light room by the rats that received rivastigmine compared to the scopolamine group $3,24,48$, and $72 \mathrm{~h}$ after the shock $(p<0.01, p<0.001)$. 
Notably, the spent time in the light chamber increased after the treatment with the extract (at all doses) 3 , 24,48 , and $72 \mathrm{~h}$ after the shock compared to the scopolamine group $(p<0.05-p<0.001)$. The animals treated with $50 \mathrm{mg} / \mathrm{kg}$ of the extract indicated no significant difference in terms of the time spent in the light $48 \mathrm{~h}$ after the shock compared to the scopolamine group. However, there were some significant differences in the time spent in the light $3,24,48$, and $72 \mathrm{~h}$ after the shock between the two groups treated with 50 and $100 \mathrm{mg} / \mathrm{kg}$ of the extract and also between the two groups treated with 100 and 200 $\mathrm{mg} / \mathrm{kg}$ of the extract $(\mathrm{p}<0.001)$.

According to the results illustrated in Fig. 4d, although the frequencies of entry to the dark chamber were higher in the scopolamine group compared to that of the control group 3, 24, and 48h post-shock delivery, the differences were not significant. The groups that received the extract at 100 and $200 \mathrm{mg} / \mathrm{kg}$ demonstrated a significant decrease in the frequencies of dark chamber entry compared to those of the scopolamine group $24(p<0.05, p<0.01)$ and $72 h(p<0.05, p<0.001)$ post-shock delivery. However, no significant decrease was found in the frequency of entry to the dark chamber in the rivastigmine group at either time point compared to the scopolamine group.

\section{Biochemical estimation}

\section{S. minor restored MDA and thiol concentration in the brain}

According to Fig. 5a, scopolamine-injected rats exhibited the elevated levels of MDA in their hippocampal and cortical tissues in comparison to the control group $(p<0.001)$. However, the rivastigmine administration significantly restored the elevated levels of MDA induced by scopolamine in the rats' hippocampus and cortex, compared to the rats of the scopolamine group $(p<0.001)$. It is notable that the treatment with all doses of the extract significantly counteracted scopolamine-induced increase in MDA level in both the hippocampus $(p<0.001)$ and cortex $(p<0.01, p<0.001)$ compared to the scopolamine group.

By determining thiol content in the hippocampal and cortical tissues, the non-enzymatic defense potential of the extract against the oxidative stress was indicated. Accordingly, the thiol concentrations in both the hippocampus and cortex of scopolamine-injected rats were significantly lower than those of the control group ( $p$ <.001). As well, the administration of rivastigmine effectively restored the scopolamine-induced decreases in thiol contents in both tissues compared to the scopolamine group $(p<0.001)$. All doses of the extract significantly restored the decreases in the concentrations of thiol caused by scopolamine in the hippocampus and cortex compared to the scopolamine group $(p<0.01, p<0.001)$ (Fig. 4b).

\section{S. minor enhanced the antioxidant defense in the brain}

As shown in Figs. $5 a$ and $b$, the antioxidant enzymes (SOD and CAT) activities were significantly attenuated in the hippocampus and cortex of the rats of the scopolamine group in comparison to those of the controls $(p<0.001)$. The treatment of these animals with rivastigmine and all doses of the administered extract resulted in a significant increase in the activities of the enzymes in the hippocampus 
and cortex $(p<0.001)$. More importantly, $200 \mathrm{mg} / \mathrm{kg}$ of the extract had the most marked effects on restoring the scopolamine-induced suppression of antioxidant enzymes $(p<0.001)$.

\section{S. minor suppressed the activity of AChE in the brain}

As shown in Fig. 7, AChE activity significantly increased in the hippocampal and cortical tissues of the scopolamine-injected rats compared to the control group $(p<0.005)$. However, the rivastigmine administration significantly reduced the AChE activity in the hippocampal and cortical tissues compared to the scopolamine group $(p<0.05, p<0.001)$. An ameliorative effect on the AChE activity in the hippocampus was found in the animals treated with different doses $(50,100$, and $200 \mathrm{mg} / \mathrm{kg}, \mathrm{p}<0.001)$ of the extract. Meanwhile, only the highest dose of the extract (i.e. $200 \mathrm{mg} / \mathrm{kg}$ ) was observed to reduce the AChE activity in the cortex significantly compared to the scopolamine group $(p<0.05)$.

\section{Discussion}

The present study was conducted on a scopolamine-induced amnesia rat model and demonstrated the beneficial effects of $S$. minor on cognitive decline. As shown by performing the passive avoidance and MWM tasks, scopolamine induced a noticeable decline in both learning and memory of the experimental rats compared to the controls. During 4 days of training in the current study, scopolamine prolonged the escape latency and distance to reach the platform. Additionally, the rats of the scopolamine group did not remember the location of the platform in probe trial and the time spent in the target quadrant decreased following the scopolamine injection. In PA task, scopolamine reduced the escape latency in the dark chamber as well as the time in the light chamber, while it prolonged the time in the dark chamber. Consistent with our findings, some previous investigations have also reported the cognition-impairing effects of scopolamine using behavioral tests (Marefati et al. 2019; Brinza et al. 2021). Accordingly, Hoang showed that the mean latencies and swimming distances increased by the administration of scopolamine (Hoang et al. 2020). Additionally, scopolamine reduced the latency to enter the darkness after shock (Ishola et al. 2020).

On the other hand, it was observed that the extract of $S$. minor effectively reversed the behavioral changes induced by scopolamine. By performing the MWM test, the ability of the rats to recall the platform location increased following the treatment with the extract, especially at the dose of $200 \mathrm{mg} / \mathrm{kg}$. Since the MWM task generally indicated spatial memory ability of rodents (Crawley 2008; D'Hooge and De Deyn 2001), so these findings suggested that $S$. minor extract boosted the rats' learning and spatial memory abilities in this study. Furthermore, in PA test, the administration of the extract improved the indices of memory in the scopolamine-treated animals. Similar results were also observed in the animals that received rivastigmine, which is a standard anti-amnesia drug considered as an AChE inhibitor. Accordingly, this drug can elevate the availability of ACh in the central cholinergic synapses and consequently ameliorate cholinergic functions (Mahdy et al. 2012). As well, the scopolamine administration to the rodents has been well-documented to induce memory loss and cognitive deficits through the inhibition of cholinergic transmission (Ishola et al. 2013; Marefati et al. 2019; Ogunsuyi et al. 
2018). Scopolamine also triggers oxidative stress by inducing an imbalance in brain oxidative status (Budzynska et al. 2015; Haider et al. 2016). Oxidative stress and cholinergic dysfunction have been previously found to be closely associated with the cognitive decline in Alzheimer's disease (Liguori et al. 2018; Dos Santos Picanco et al., 2018). Our data revealed that scopolamine-induced memory loss was accompanied with increase in AChE activity and oxidative stress in the brain tissue. These results are in line with those of the previous studies (Marefati et al. 2019; Brinza et al. 2021; Boiangiu et al. 2020). In this regard, Brinza et al. (2021) reported a significant reduction in the total antioxidant content along with the increased AChE activity. Notably, the impairment of endogenous antioxidant defense systems is known as a key factor in the scopolamine-dependent cognitive impairment (Haider et al. 2016; Muhammad et al. 2019). On the other hand, some compounds with antioxidant properties like ascorbic acid has also exhibited an improving effect on scopolamine-induced cognitive deficits via inhibiting AChE activity and attenuating oxidative injury (Ishola et al. 2013; Harrison et al. 2009).

In the current research, the extract restored oxidative stress parameters levels disturbed by the administered scopolamine. The extract and rivastigmine significantly reduced lipid peroxidation while, they enhanced total thiol content, SOD, and CAT in the cortex and hippocampus. Additionally, AChE activity was attenuated after the treatment with both the extract and rivastigmine. Accordingly, rivastigmine also exhibited antioxidant activities in an animal model of Alzheimer's disease (Mahdy et al. 2012). Moreover, it was previously shown that rivastigmine causes memory consolidation and acquisition. The compounds with AChE inhibiting properties such as rivastigmine were found to reduce cognitive impairments induced by scopolamine (Howes and Houghton 2003).

Our findings suggested that the inhibition of oxidative stress may contribute to memory enhancing effects of the extract in the rats, which was also reported in previous studies (Soodi et al. 2017; Nguyen et al. 2008; Akbari et al. 2019). Ferreira et al. (2006) claimed the anti-oxidant and AChE inhibitory potentials of the ethanol extract and essential oil of $S$. minor. Another study also showed neuroprotective effects of $S$. minor on oxidative injury induced by amyloid $\beta$ in cultured cerebellar granule neurons (Soodi et al. 2017). Furthermore, the AChE inhibitory properties has been proposed to be involved in the neuroprotective effect of $S$. minor on amyloid $\beta$ toxicity in primary neural cell culture (Akbari et al. 2019).

As previously reported, the phenolic and flavonoid compounds present in $S$. minor extract contribute to its antioxidant and neuroprotective functions (Akbari et al. 2019; Cirovic et al. 2020). In this regard, various phenolic compounds, including quercetin and ellagic acid, were observed to alleviate cognitive deficits in the experimental models (Dornelles et al. 2020; Molaei et al. 2020). Different bioactive components were also identified in S. mninor extract, including quercetin, myricetin, kaempferol, ellagic acid, catechin, gallic acid, and their derivatives. Hence, the alleviation of cholinergic dysfunction and subsequently memoryenhancing effect of $S$. mninor extract may be attributed to the presence of the components with antioxidant activities.

\section{Conclusions}


The present study provided some evidence that the hydro-ethanolic extract of $S$. minor could ameliorate the scopolamine-induced memory deficits in rats as shown by the data obtained from the MWM and PA tasks data. In addition, the neuroprotective potential of $S$. minor extract may be partly linked to its antiAChE and antioxidant activities in the brain tissue. Therefore, S. minormay be a candidate for the prevention or treatment of the cognitive disorders. However, further in vivo and clinical studies should be done before application of this herbal extract for treatment of human amnesia.

\section{Declarations}

\section{Acknowledgments}

This paper was financially supported by Vice Chancellor for Research and Technology (grant number 980349), Mashhad University of Medical Sciences, Mashhad, Iran.

\section{Conflict of interest}

The authors declare no conflict of interest.

\section{Acknowledgments}

The authors appreciate the Vice Chancellor for Research and Technology, Mashhad University of Medical Sciences for financial support (NO: 980349).

Author contributions Arezoo Rajabian and Mahmoud Hosseini conducted conception and design of the project. Zeinab Hosseini, Fatemeh Mansouritorghabeh, Faezeh Sadat Hosseini Kakhki, and Arezoo Rajabian performed the experiments. Arezoo Rajabian and Mahmoud Hosseini performed statistical analysis and wrote the manuscript. Hassan Rakhshandeh, Maede Hasanpour, Mehrdad Iranshahi, and Azar Hosseini provided the plant and LC-Ms analysis. All authors contributed to manuscript preparation and approved the submitted version.

Funding This study was funded by Vice Chancellor for Research and Technology, Mashhad University of Medical Sciences with the following grant number: 980349

\section{Compliance with ethical standards}

\section{Conflict of interest}

The authors declare no conflict of interest.

\section{Ethical approval}

All procedures performed in this study including animals were in accordance with the National Institutes of Health Guide for the Care and Use of Laboratory Animals and were approved by Ethical Committee of 
the Animal Research of Mashhad University of Medical Sciences (Ethical code: IR.MUMS.MEDICAL.REC.1398.655).

\section{Data availability statement}

The authors confirm that all data generated or analyzed during this study are included in this published article.

\section{References}

1. Akbari S, Soodi M, Hajimehdipoor H, Ataei N (2019) Protective effects of Sanguisorba minorand Ferulago angulata total extracts against beta-amyloid induced cytotoxicity and oxidative stress in cultured cerebellar granule neurons. J Herbmed Pharmacol 8(3):248-55. doi: 10.15171/jhp.2019.36.

2. Ayoub NA (2003) Unique phenolic carboxylic acids from Sanguisorba minor. Phytochemistry 63(4):433-436. doi: 10.1016/s0031-9422(03)00198-5.

3. Bavarsad K, Hadjzadeh MA, Hosseini M, Pakdel R, Beheshti F, Bafadam S, Ashaari Z (2020) Effects of levothyroxine on learning and memory deficits in a rat model of Alzheimer's disease: the role of BDNF and oxidative stress. Drug Chem Toxicol 43(1):57-63. doi: 10.1080/01480545.2018.1481085.

4. Boiangiu RS, Brinza I, Hancianu M, Erdogan Orhan I, Eren G, Gündüz E, Ertas H, Hritcu L, Cioanca O (2020) Cognitive facilitation and antioxidant effects of an essential oil mix on scopolamine-induced amnesia in Rats: Molecular modeling of in vitro and in vivo approaches. Molecules 25(7):1519. doi: 10.3390/molecules25071519.

5. Brinza I, Boiangiu RS, Hancianu M, Cioanca O, Erdogan Orhan I, Hritcu L (2021) Bay Leaf (Laurus Nobilis L.) incense improved scopolamine-induced amnesic rats by restoring cholinergic dysfunction and brain antioxidant status. Antioxidants (Basel) 10(2):259. doi: 10.3390/antiox10020259.

6. Budzynska B, Boguszewska-Czubara A, Kruk-Slomka M, Skalicka-Wozniak K, Michalak A, Musik I, Biala G (2015) Effects of imperatorin on scopolamine-induced cognitive impairment and oxidative stress in mice. Psychopharmacology (Berl) 232(5):931-942. doi: 10.1007/s00213-014-3728-6.

7. Bunse M, Lorenz P, Stintzing FC, Kammerer DR (2020) Characterization of secondary metabolites in flowers of Sanguisorba officinalis L. by HPLC-DAD-MSn and GC/MS. Chem Biodivers 17(4):e1900724. doi: 10.1002/cbdv.201900724.

8. Cirovic T, Barjaktarevic A, Ninkovic M, Bauer R, Nikles S, Brankovic S, Markovic M, Jovanovic VS, llic M, Milovanovic 0, 2020. Biological activities of Sanguisorba minor L. extracts-in vitro and in vivo evaluations. Acta Poloniae Pharmaceutica - Drug Research, 77(5), 745-758.

9. Crawley JN (2008) Behavioral phenotyping strategies for mutant mice. Neuron 57(6):809-818. doi: 10.1016/j.neuron.2008.03.001.

10. D'Hooge R, De Deyn PP (2001) Applications of the Morris water maze in the study of learning and memory. Brain Res Brain Res Rev 36(1):60-90. doi: 10.1016/s0165-0173(01)00067-4. 
11. Deb D, Bairy KL, Nayak V, Rao M (2015) Comparative effect of lisinopril and fosinopril in mitigating learning and memory deficit in scopolamine-induced amnesic rats. Adv Pharmacol Sci 2015 : 521718. doi: 10.1155/2015/521718.

12. Dornelles GL, de Oliveira JS, de Almeida EJR, Mello CBE, E Rodrigues BR, da Silva CB, Petry LDS, Pillat MM, Palma TV, de Andrade CM (2020) Ellagic acid inhibits neuroinflammation and cognitive impairment induced by lipopolysaccharides. Neurochem Res 45(10):2456-2473. doi: 10.1007/s11064-020-03105-z.

13. Dos Santos Picanco LC, Ozela PF, de Fatima de Brito Brito M, Pinheiro AA, Padilha EC, Braga FS, de Paula da Silva CHT, Dos Santos CBR, Rosa JMC, da Silva Hage-Melim LI (2018) Alzheimer's Disease: A Review from the Pathophysiology to Diagnosis, New Perspectives for Pharmacological Treatment. Curr Med Chem 25(26):3141-3159. doi: 10.2174/0929867323666161213101126.

14. El-Marasy SA, El-Shenawy SM, El-Khatib AS, El-Shabrawy OA, Kenawy SA (2012) Effect of Nigella sativa and wheat germ oils on scopolamine-induced memory impairment in rats. Bull Fac Pharm Cairo Unic 50(2):81-88. https://doi.org/10.1016/j.bfopcu.2012.05.001

15. Ellman GL, Courtney KD, Andres V Jr, Feather-stone RM (1961) A new and rapid colorimetric determination of acetylcholinesterase activity. Biochem Pharmacol 7:88-95. doi: 10.1016/00062952(61)90145-9.

16. Ferreira A, Proença C, Serralheiro ML, Araújo ME (2006) The in vitro screening for acetylcholinesterase inhibition and antioxidant activity of medicinal plants from Portugal. J Ethnopharmacol 108(1):31-37. doi: 10.1016/j.jep.2006.04.010.

17. Finimundy TC, Karkanis A, Fernandes Â, Petropoulos SA, Calhelha R, Petrović J, Soković M, Rosa E, Barros L, Ferreira ICFR (2020) Bioactive properties of Sanguisorba minor L. cultivated in central Greece under different fertilization regimes. Food Chem 327:127043. doi:

10.1016/j.foodchem.2020.127043.

18. Ghasemi S, Moradzadeh M, Hosseini M, Beheshti F, Sadeghnia HR (2019) Beneficial effects of Urtica dioica on scopolamine-induced memory impairment in rats: protection against acetylcholinesterase activity and neuronal oxidative damage. Drug Chem Toxicol 42(2):167-175. doi: 10.1080/01480545.2018.1463238.

19. Giovannini MG, Lana D, Pepeu G (2015) The integrated role of ACh, ERK and mTOR in the mechanisms of hippocampal inhibitory avoidance memory. Neurobiol Learn Mem 119:18-33. doi: 10.1016/j.nlm.2014.12.014.

20. Haider S, Tabassum S, Perveen T (2016) Scopolamine-induced greater alterations in neurochemical profile and increased oxidative stress demonstrated a better model of dementia: A comparative study. Brain Res Bull 127:234-247. doi: 10.1016/j.brainresbull.2016.10.002.

21. Harrison FE, Hosseini AH, Dawes SM, Weaver S, May JM (2009) Ascorbic acid attenuates scopolamine-induced spatial learning deficits in the water maze. Behav Brain Res 205(2):550-558. doi: 10.1016/j.bbr.2009.08.017. 
22. Hasselmo ME (2006) The role of acetylcholine in learning and memory. Curr Opin Neurobiol 16(6):710-715. doi: 10.1016/j.conb.2006.09.002.

23. Hoang THX, Ho DV, Van Phan K, Le QV, Raal A, Nguyen HT (2020) Effects of Hippeastrum reticulatum on memory, spatial learning and object recognition in a scopolamine-induced animal model of Alzheimer's disease. Pharm Biol 58(1):1098-1104. doi: 10.1080/13880209.2020.1841810.

24. Howes MJ, Houghton PJ (2003) Plants used in Chinese and Indian traditional medicine for improvement of memory and cognitive function. Pharmacol Biochem Behav 75(3):513-527. doi: 10.1016/s0091-3057(03)00128-x.

25. Ishola IO, Akinyede AA, Eloke JE, Chaturvedi JP, Narender T (2020) Diastereomeric mixture of calophyllic and isocalophyllic acid ameliorates scopolamine-induced memory impairment in mice: involvement of antioxidant defense and cholinergic systems. Neurotox Res 37(1):58-66. doi: 10.1007/s12640-019-00117-8.

26. Ishola IO, Tota S, Adeyemi OO, Agbaje EO, Narender T, Shukla R (2013) Protective effect of Cnestis ferruginea and its active constituent on scopolamine-induced memory impairment in mice: a behavioral and biochemical study. Pharm Biol 51(7):825-835. doi: 10.3109/13880209.2013.767360.

27. Jang E, Inn KS, Jang YP, Lee KT, Lee JH (2018) Phytotherapeutic Activities of Sanguisorba officinalis and its Chemical Constituents: A Review. Am J Chin Med 46(2):299-318. doi:

10.1142/S0192415X18500155.

28. Karkanis A, Vellios E, Thomaidis T, Bilalis D, Travlos I (2014) Phytochemistry and Biological Properties of Burnet Weed (Sanguisorba spp.): A Review. Not Sci Biol 6(4):395-398. DOI:10.1583/nsb649471

29. Kim S, Oh S, Noh HB, Ji S, Lee SH, Koo JM, Choi CW, Jhun (2018) In Vitro Antioxidant and antipropionibacterium acnes activities of cold water, hot water, and methanol extracts, and their respective ethyl acetate fractions, from Sanguisorba officinalis L. Roots. Molecules 23(11):3001. doi: 10.3390/molecules23113001.

30. Klinkenberg I, Blokland A (2010) The validity of scopolamine as a pharmacological model for cognitive impairment: a review of animal behavioral studies. Neurosci Biobehav Rev 34(8):13071350. doi: 10.1016/j.neubiorev.2010.04.001.

31. Lee JS, Kim HG, Lee HW, Han JM, Lee SK, Kim DW, Saravanakumar A, Son CG (2015) Hippocampal memory enhancing activity of pine needle extract against scopolamine-induced amnesia in a mouse model. Sci Rep 5:9651. doi: 10.1038/srep09651.

32. Leuner K, Schütt T, Kurz C, Eckert SH, Schiller C, Occhipinti A, Mai S, Jendrach M, Eckert GP, Kruse SE (2012) Mitochondrion-derived reactive oxygen species lead to enhanced amyloid beta formation. Antioxid Redox Signal 16(12):1421-1433. doi: 10.1089/ars.2011.4173.

33. Li Q, He S, Chen Y, Feng F, Qu W, Sun H (2018) Donepezil-based multi-functional cholinesterase inhibitors for treatment of Alzheimer's disease. Eur J Med Chem 158:463-477. doi: 10.1016/j.ejmech.2018.09.031. 
34. Liguori I, Russo G, Curcio F, Bulli G, Aran L, Della-Morte D, et al (2018) Oxidative stress, aging, and diseases. Clin Interv Aging 13:757-772. doi: 10.2147/CIA.S158513.

35. Madesh M, Balasubramanian KA (1998) Microtiter plate assay for superoxide dismutase using MTT reduction by superoxide. Indian J Biochem Biophys 35(3):184-188.

36. Mahdy K, Shaker O, Wafay H, Nassar Y, Hassan H, Hussein A (2012) Effect of some medicinal plant extracts on the oxidative stress status in Alzheimer's disease induced in rats. Eur Rev Med Pharmacol Sci 16 Suppl 3:31-42.

37. Marefati N, Mokhtari-Zaer A, Beheshti F, Karimi S, Mahdian Z, Khodamoradi M, Hosseini M (2019) The effects of soy on scopolamine-induced spatial learning and memory impairments are comparable to the effects of estradiol. Horm Mol Biol Clin Investig 39(3):20180084. doi: 10.1515/hmbci-2018-0084.

38. Melo JB, Agostinho P, Oliveira CR (2003) Involvement of oxidative stress in the enhancement of acetylcholinesterase activity induced by amyloid beta-peptide. Neurosci Res 45(1):117-27. doi: 10.1016/s0168-0102(02)00201-8.

39. Molaei A, Hatami H, Dehghan G, Sadeghian R, Khajehnasiri N (2020) Synergistic effects of quercetin and regular exercise on the recovery of spatial memory and reduction of parameters of oxidative stress in animal model of Alzheimer's disease. EXCLI J 19:596-612. doi: 10.17179/excli2019-2082.

40. Morris R (1984) Developments of a water-maze procedure for studying spatial learning in the rat. J Neurosci Methods11(1):47-60. doi: 10.1016/0165-0270(84)90007-4.

41. Muhammad T, Ali T, Ikram M, Khan A, Alam SI, Kim MO (2019) Melatonin rescue oxidative stressmediated neuroinflammation/ neurodegeneration and memory impairment in scopolamine-induced amnesia mice model. J Neuroimmune Pharmacol 14(2):278-294. doi: 10.1007/s11481-018-9824-3.

42. Murai Y, Iwashina T (2016) Phenolic Compounds from Sanguisorba obtusa Endemic to Japan. Bull Natl Mus Nat Sci Ser B 42(4):143-147.

43. Ng TP, Chiam PC, Lee T, Chua HC, Lim L, Kua EH (2006) Curry consumption and cognitive function in the elderly. Am J Epidemiol 164(9):898-906. doi: 10.1093/aje/kwj267.

44. Nguyen TT, Cho SO, Ban JY, Kim JY, Ju HS, Koh SB, Song KS, Seong YH (2008) Neuroprotective effect of Sanguisorbae radix against oxidative stress-induced brain damage: in vitro and in vivo. Biol Pharm Bull 31(11):2028-35. doi: 10.1248/bpb.31.2028.

45. Norouzi F, Hosseini M, Abareshi A, Beheshti F, Khazaei M, Shafei MN, Soukhtanloo M, Gholamnezhad Z (2019) Memory enhancing effect of Nigella Sativa hydro-alcoholic extract on lipopolysaccharideinduced memory impairment in rats. Drug Chem Toxicol 42(3):270-279. doi: 10.1080/01480545.2018.1447578.

46. Ogunsuyi OB, Ademiluyi AO, Oboh G, Oyeleye SI, Dada AF (2018) Green leafy vegetables from two Solanum spp. (Solanum nigrum L and Solanum macrocarpon L) ameliorate scopolamine-induced cognitive and neurochemical impairments in rats. Food Sci Nutr 6(4):860-870. doi: 10.1002/fsn3.628. 
47. Parfitt GM, Campos RC, Barbosa AK, Koth AP, Barros DM (2012) Participation of hippocampal cholinergic system in memory persistence for inhibitory avoidance in rats. Neurobiol Learn Mem 97(2):183-8. doi: 10.1016/j.nIm.2011.12.001.

48. Rajabian A, Boroushaki MT, Hayatdavoudi P, Sadeghnia HR (2016) Boswellia serrata protects against glutamate-induced oxidative stress and apoptosis in PC12 and N2a cells. DNA Cell Biol 35(11):666679. doi: $10.1089 /$ dna.2016.3332.

49. Soodi M, Hajimehdipoor H, Akbari S, Ataei N (2017) Screening seven Iranian medicinal plants for protective effects against $\beta$-Amyloid-induced cytotoxicity in cultured cerebellar granule neurons. Research J Pharmacognosy 4(2):15-22.

50. Spínola V, Castilho PC (2017) Evaluation of asteraceae herbal extracts in the management of diabetes and obesity. Contribution of caffeoylquinic acids on the inhibition of digestive enzymes activity and formation of advanced glycation end-products (in vitro). Phytochemistry 143:29-35. doi: 10.1016/j.phytochem.2017.07.006.

51. Su XD, Ali I, Arooj M, Koh YS, Yang SY, Kim YH (2018) Chemical constituents from Sanguisorba officinalis L. and their inhibitory effects on LPS-stimulated pro-inflammatory cytokine production in bone marrow-derived dendritic cells. Arch Pharm Res 41(5):497-505. doi: 10.1007/s12272-018-10351.

52. Sun K, Bai Y, Zhao R, Guo Z, Su X, Li P, Yang P (2019) Neuroprotective effects of matrine on scopolamine-induced amnesia via inhibition of AChE/BuChE and oxidative stress. Metab Brain Dis 34(1):173-181. doi: 10.1007/s11011-018-0335-y.

53. Terry AV Jr, Callahan PM, Hall B, Webster SJ (2011) Alzheimer's disease and age-related memory decline (preclinical). Pharmacol Biochem Behav 99(2):190-210. doi: 10.1016/j.pbb.2011.02.002.

54. Zhao Z, He X, Zhang Q, Wei X, Huang L, Fang JC, Wang X, Zhao M, Bai Y, Zheng X (2017) Traditional Uses, Chemical Constituents and Biological Activities of Plants from the Genus Sanguisorba L. Am J Chin Med 45(2):199-224. doi: 10.1142/S0192415X17500136.

\section{Tables}

Table 1. Peak assignment of metabolites in S. minor hydro-ethanolic extract using LC-MS in the negative mode. 


\begin{tabular}{|c|c|c|c|c|}
\hline $\begin{array}{l}\text { Peak } \\
\text { No. }\end{array}$ & Compound & $\begin{array}{l}\mathrm{RT} \\
(\min )\end{array}$ & $\begin{array}{l}{[\mathrm{M}-1]} \\
(\mathrm{m} / z)\end{array}$ & Reference \\
\hline 1 & Galloyl glucoside & 52.2 & 331.26 & $\begin{array}{l}\text { (Bunse et al. 2020; Murai and } \\
\text { Iwashina, 2016) }\end{array}$ \\
\hline 2 & Galloylquinic acid & 52.5 & 343.44 & (Bunse et al. 2020) \\
\hline 3 & Methylgallate hexoside & 36.7 & 345.12 & (Bunse et al. 2020) \\
\hline 4 & 5-Caffeoylquinic acid & 3.2 & 353.10 & (Bunse et al. 2020) \\
\hline 5 & Coumaroylquinic acid & 83.8 & 337.38 & (Bunse et al. 2020) \\
\hline 6 & Roseoside & 56.1 & 431.22 & (Bunse et al. 2020) \\
\hline 7 & p-Coumaroyl hexoside & 83.7 & 325.68 & (Bunse et al. 2020) \\
\hline 8 & Ellagic acid & 54.2 & 381.36 & $\begin{array}{l}\text { (Bunse et al. 2020; Murai and } \\
\text { Iwashina 2016; Jang et al. } \\
\text { 2018) }\end{array}$ \\
\hline 9 & Kaempferol-3-glucuronide & 2.9 & 461.28 & (Murai and Iwashina 2016) \\
\hline 10 & Ellagic acid derivative & 62.4 & 451.62 & (Murai and Iwashina 2016) \\
\hline 11 & $\beta$-glucogallin & 52.3 & 331.14 & $\begin{array}{l}\text { (Ayoub 2003; Karkanis et al. } \\
\text { 2014) }\end{array}$ \\
\hline 12 & Quercetin & 15.3 & 301.14 & $\begin{array}{l}\text { (Murai and Iwashina 2016; Jang } \\
\text { et al. 2018; Karkanis et al. 2014) }\end{array}$ \\
\hline 13 & Arjunic acid & 43.8 & 489.24 & (Kim et al. 2018) \\
\hline 14 & Catechin & 75.0 & 289.26 & (Su et al. 2018) \\
\hline 15 & Taxifolin-3-glucopyranoside & 63.8 & 465.66 & (Su et al. 2018) \\
\hline 16 & $\begin{array}{l}\text { (2E)-3,7-Dimethyl-2,6-octadien-1-yl 6-O-a- } \\
\text { Larabinofuranosyl-b-D-glucopyranoside }\end{array}$ & 42.0 & 447.24 & (Su et al. 2018) \\
\hline 17 & 2,3-(S)-Hexahydroxydiphenoyl-D-glucose & 57.9 & 481.14 & (Ayoub 2003) \\
\hline 18 & $\begin{array}{l}\text { 4,8-Dimethoxy-7-hydroxy-2-oxo-2H-1- } \\
\text { benzopyran5,6-dicarboxylic acid }\end{array}$ & 84.2 & 309.66 & (Ayoub, 2003) \\
\hline \multirow[t]{2}{*}{19} & $\begin{array}{l}\text { 2-(4-Carboxy-3-methoxystyryl)-2- } \\
\text { methoxysuccinic }\end{array}$ & 94.2 & 322.08 & (Ayoub 2003) \\
\hline & acid & & & \\
\hline 20 & Coumaroylquinic acid & 84.0 & 337.5 & \\
\hline
\end{tabular}


(Bunse et al. 2020; Spínola and Castilho 2017)

\begin{tabular}{|llccc|}
\hline 21 & Kaempferol & 43.7 & 285.24 & $\begin{array}{l}\text { (Ayoub 2003, Murai and } \\
\text { Iwashina 2016) }\end{array}$ \\
\hline 22 & Quercetin-3-O-glucuronide & 1.3 & 477.00 & $\begin{array}{l}\text { (Ayoub 2003; Murai and } \\
\text { Iwashina 2016) }\end{array}$ \\
\hline 23 & Oleic acid & 50.3 & 281.16 & (Kim et al. 2018) \\
\hline 24 & Myricetin & 10.6 & 317.04 & (Kim et al. 2018) \\
\hline 26 & Catechin gallate & 84.5 & 441.48 & (Kim et al. 2018) \\
\hline
\end{tabular}

\section{Figures}

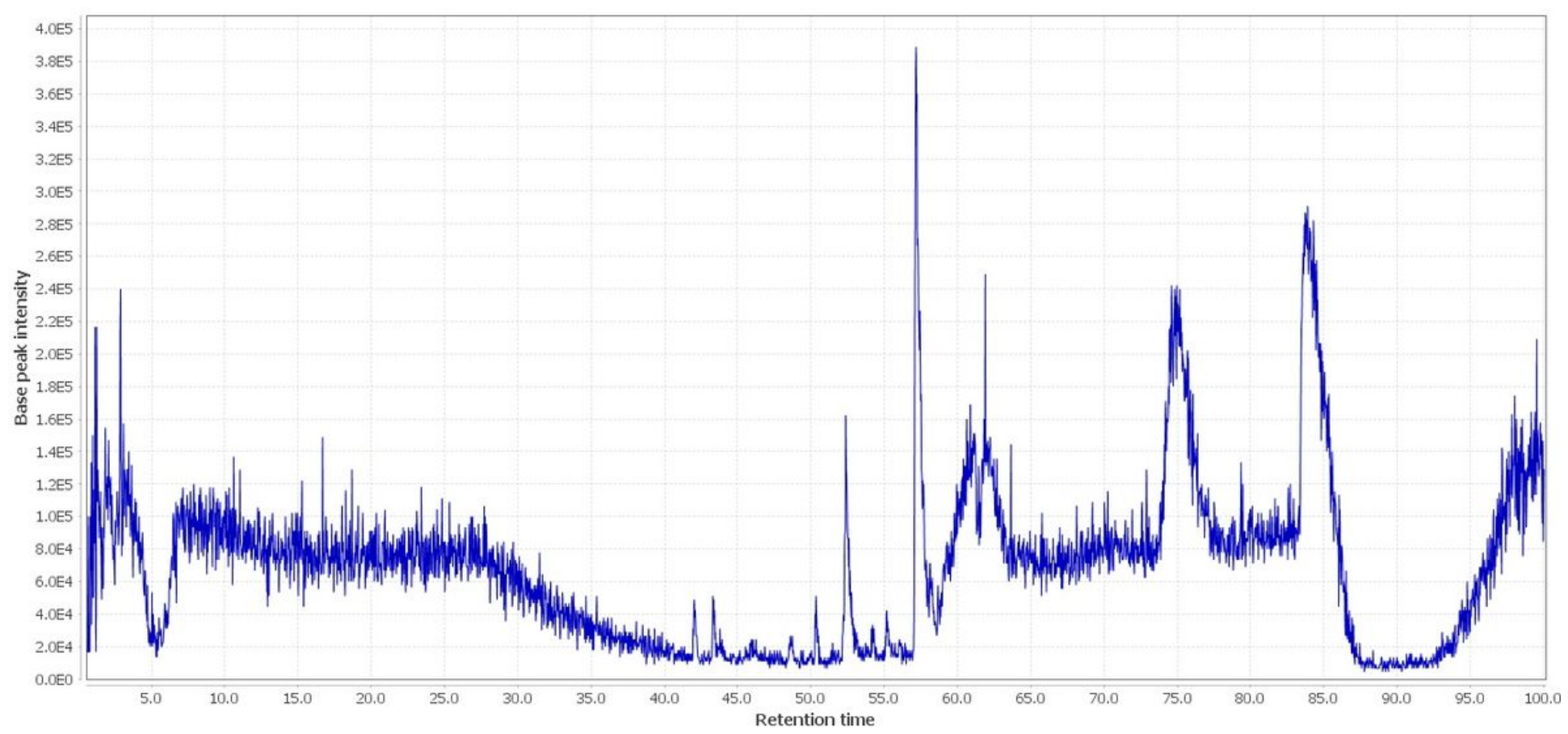

\section{Figure 1}

The total ion chromatogram of S. minor hydro-ethanolic extract using LC-MS in the positive mode. 


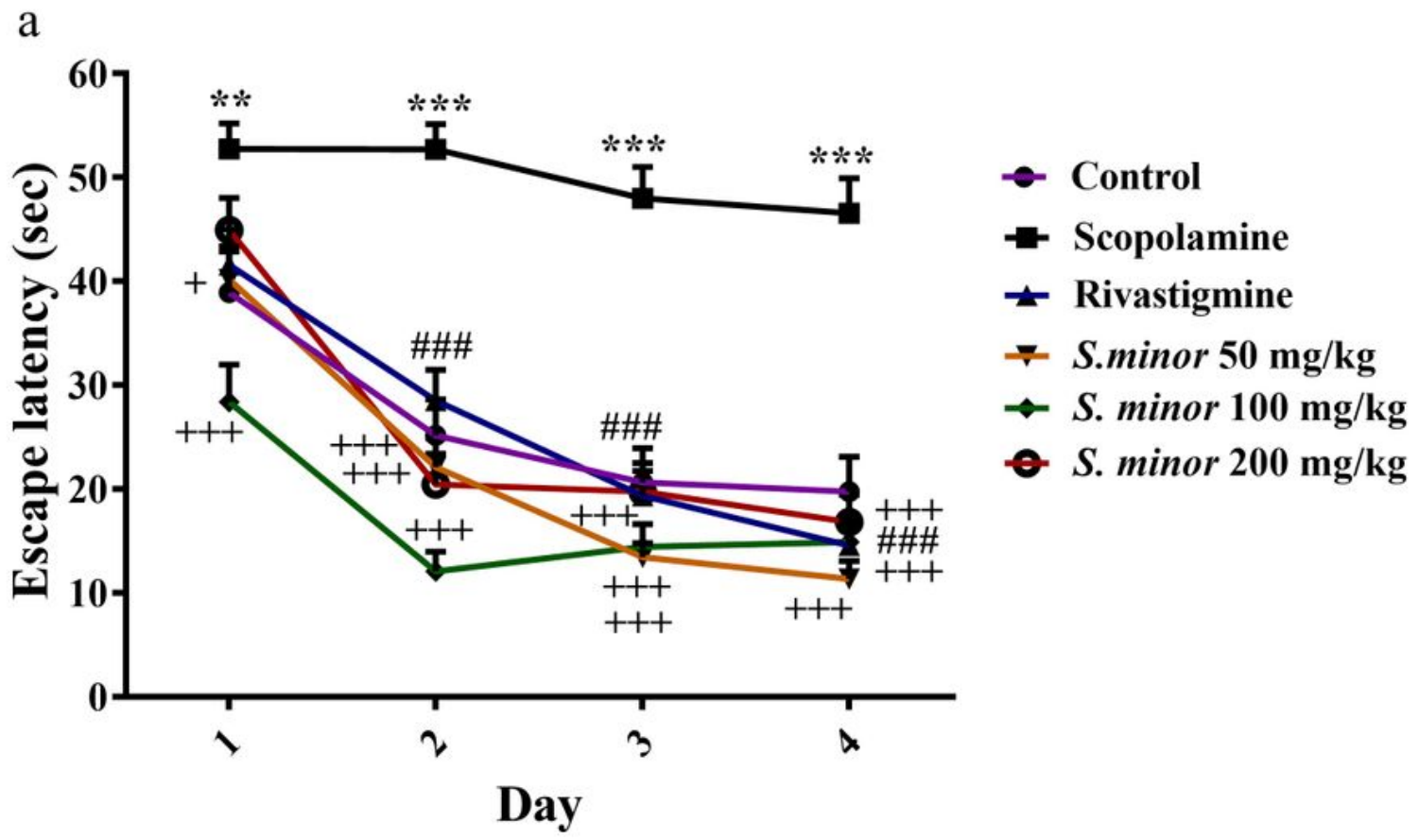

b

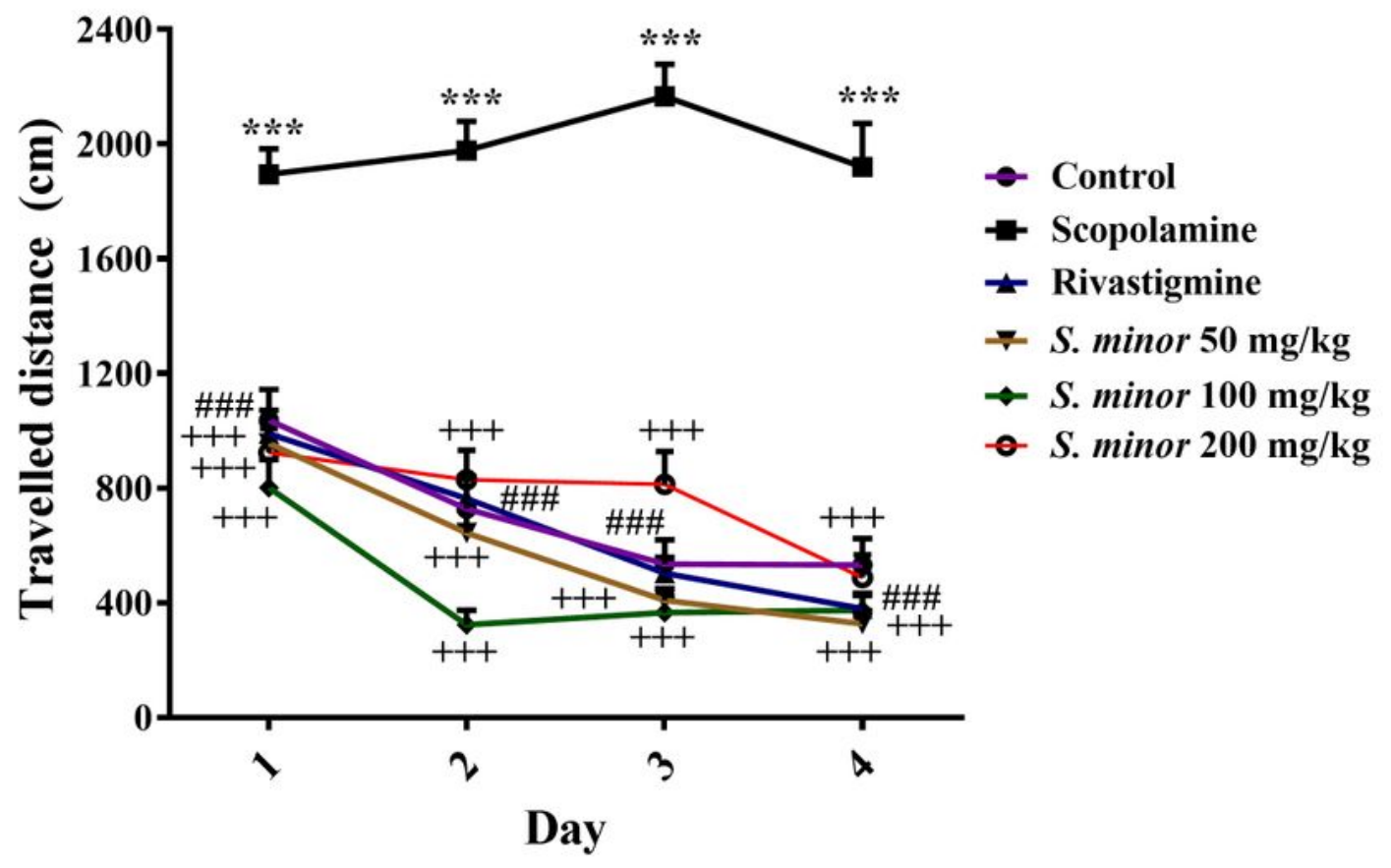

Figure 2

Effect of S. minor hydro-ethanolic extract on scopolamine-induced memory deficit. (a) Escape latency (b) travelled distance of the rats to reach to the platform during the 4 days of training trails were assessed using Morris Water Maze task. Values were expressed as mean \pm SEM $(n=10) .{ }^{* \star} p<0.01$, ${ }^{\star \star \star} p<0.001$ Scopolamine group Vs. the control group. \#\#\#p<0.001 Rivastigmin group Vs. Scopolamin group; $+p<$ $0.05,+++p<0.001 \mathrm{~S}$. minor extract Vs. Scopolamin group. 

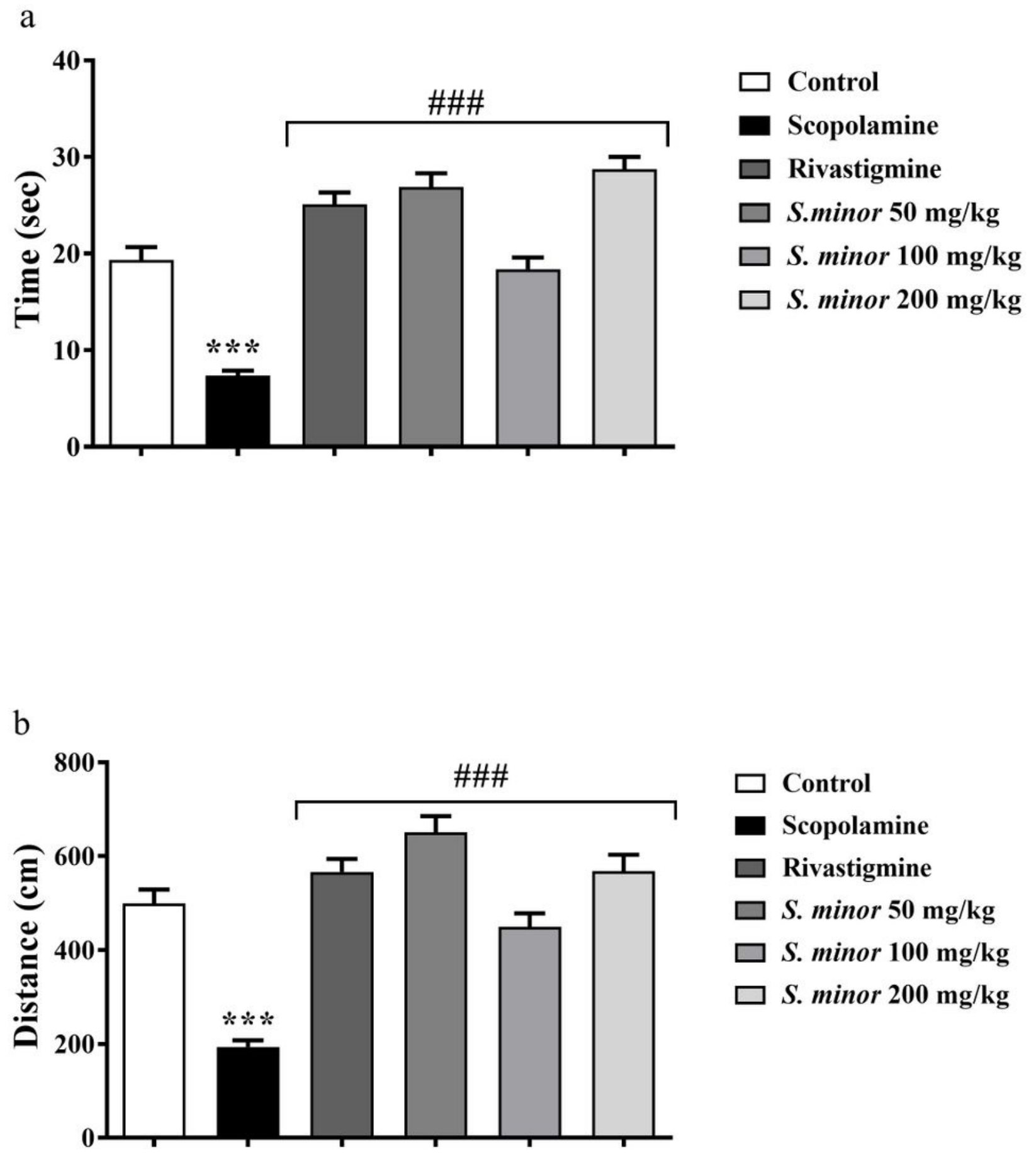

Figure 3

Effect of S. minor hydro-ethanolic extract on scopolamine-induced memory deficit. (a) Time spent (b) Traveled distance of the rats in the target quadrant in the prob trail were assessed using Morris Water Maze task. Values were expressed as mean \pm SEM $(n=10)$. ${ }^{* \star} p<0.001$ Scopolamine group Vs. control group; \#\#\#p<0.01 S. minor extract and rivastigmine Vs. scopolamine group 

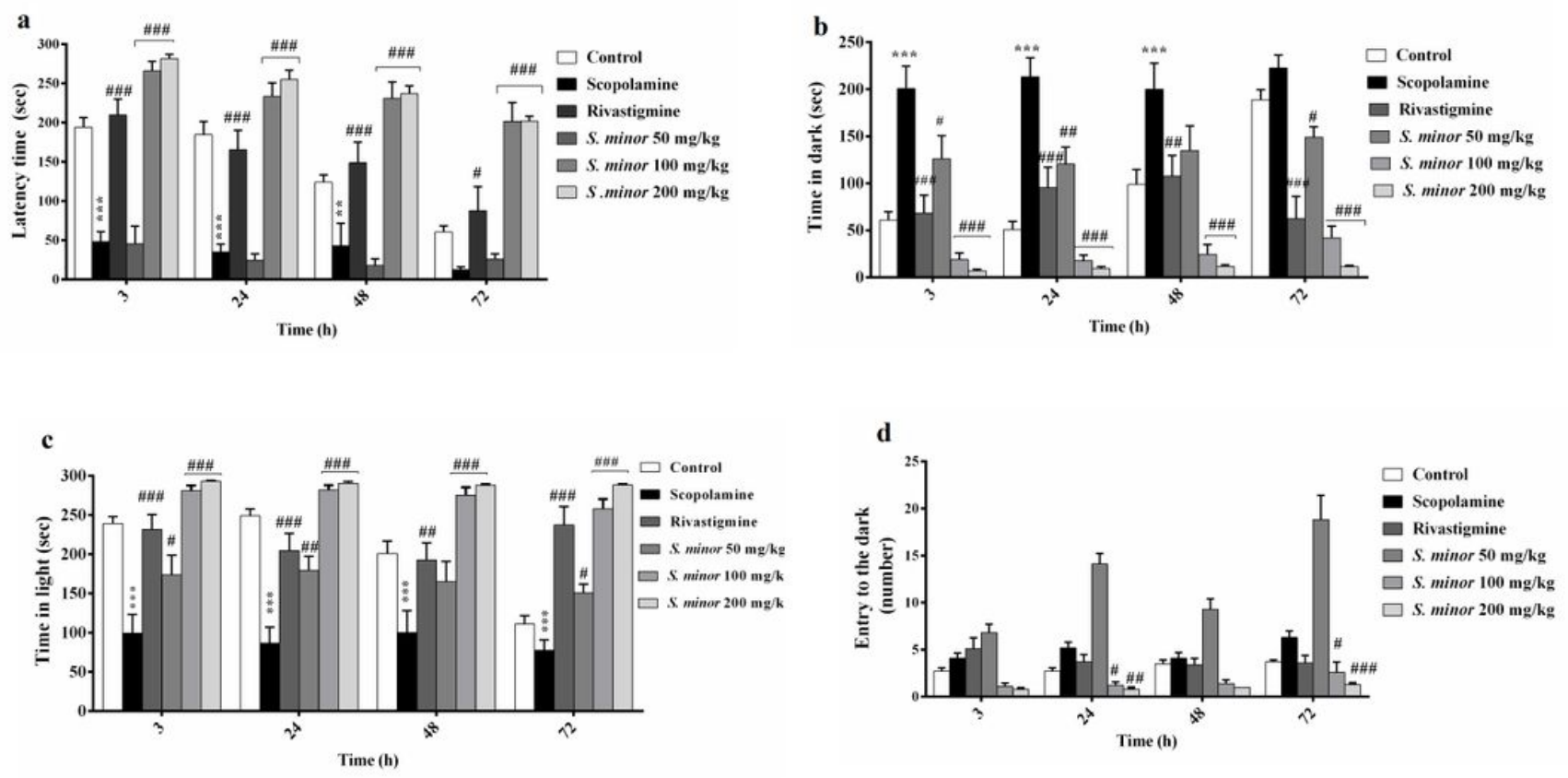

\section{Figure 4}

Effect of S. minor hydro-ethanolic extract on scopolamine-induced memory deficit. (a) latency time (b) the time spent in the dark (c) the time spent in the light (d) The frequency of entries to the dark compartment were assessed using passive avoidance test. Values were expressed as mean \pm SEM $(n=$ 10). ${ }^{\star \star \star} p<0.001$ Scopolamine group Vs. the control group; $\# p<0.05$, \#\#p $<0.01$, \#\#\# $p<0.001$ S. minor extract and rivastigmine Vs. Scopolamine group. 

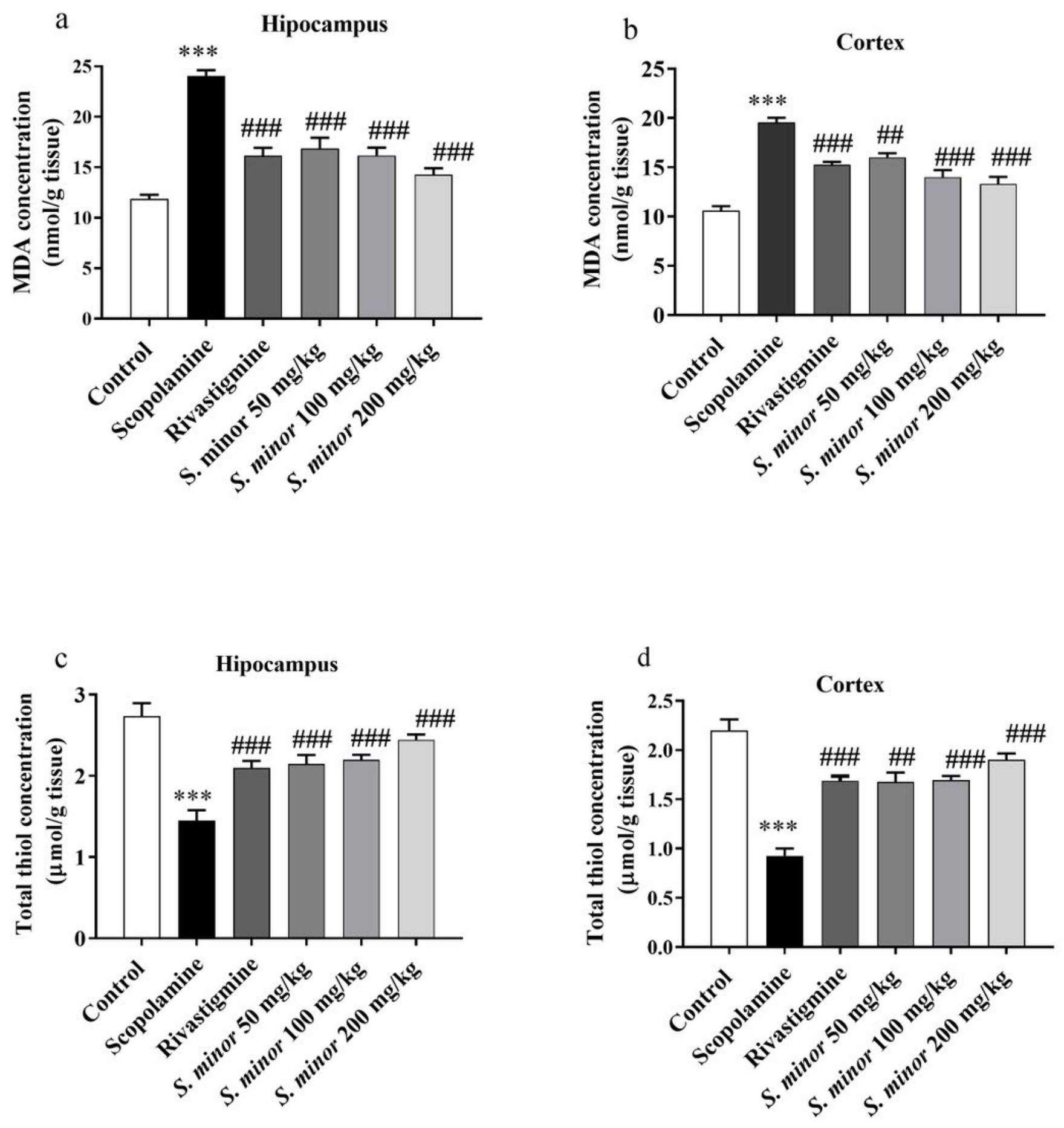

Figure 5

Effect of S. minor hydro-ethanolic extract on $\operatorname{MDA}(a, b)$ and thiol concentration $(c, d)$ in hipocampus and cortex of scopolamine-treated rats. Values were expressed as mean \pm SEM $(n=10)$. ${ }^{\star \star *} p<0.001$ Scopolamine group Vs. the control group; \#\#p<0.01, \#\#\# p<0.001 S. minor extract and rivastigmine Vs. Scopolamine group. 

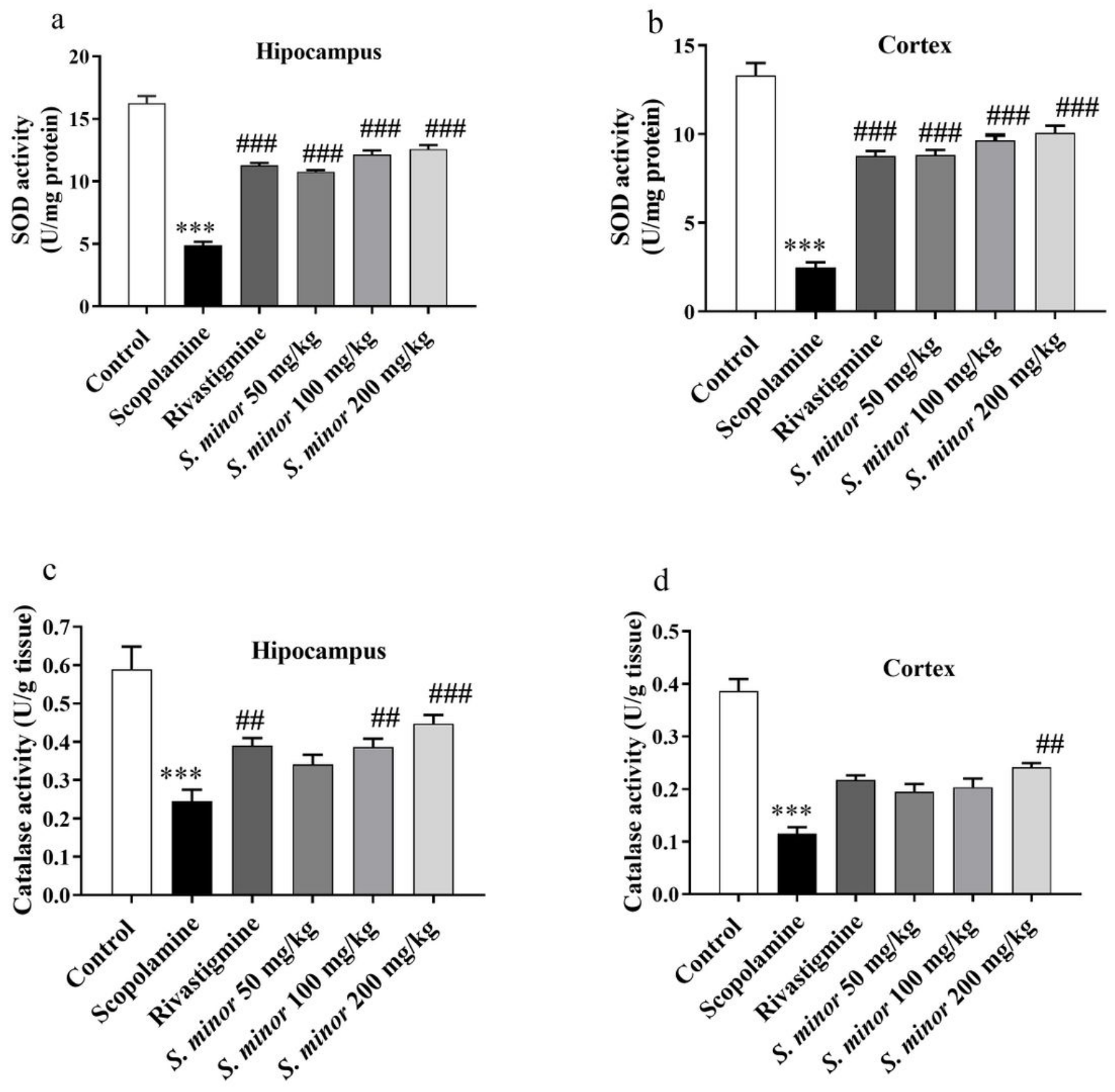

Figure 6

Effect of S. minor hydro-ethanolic extract on $\operatorname{SOD}(a, b)$ and catalase activities $(c, d)$ in hipocampus and cortex of scopolamine-treated rats. Values were expressed as mean \pm SEM $(n=10)$. ${ }^{* \star} p<0.001$ Scopolamine group Vs. the control group; \#\#p<0.01, \#\#\# p<0.001 S. minor extract and rivastigmine Vs. Scopolamine group. 

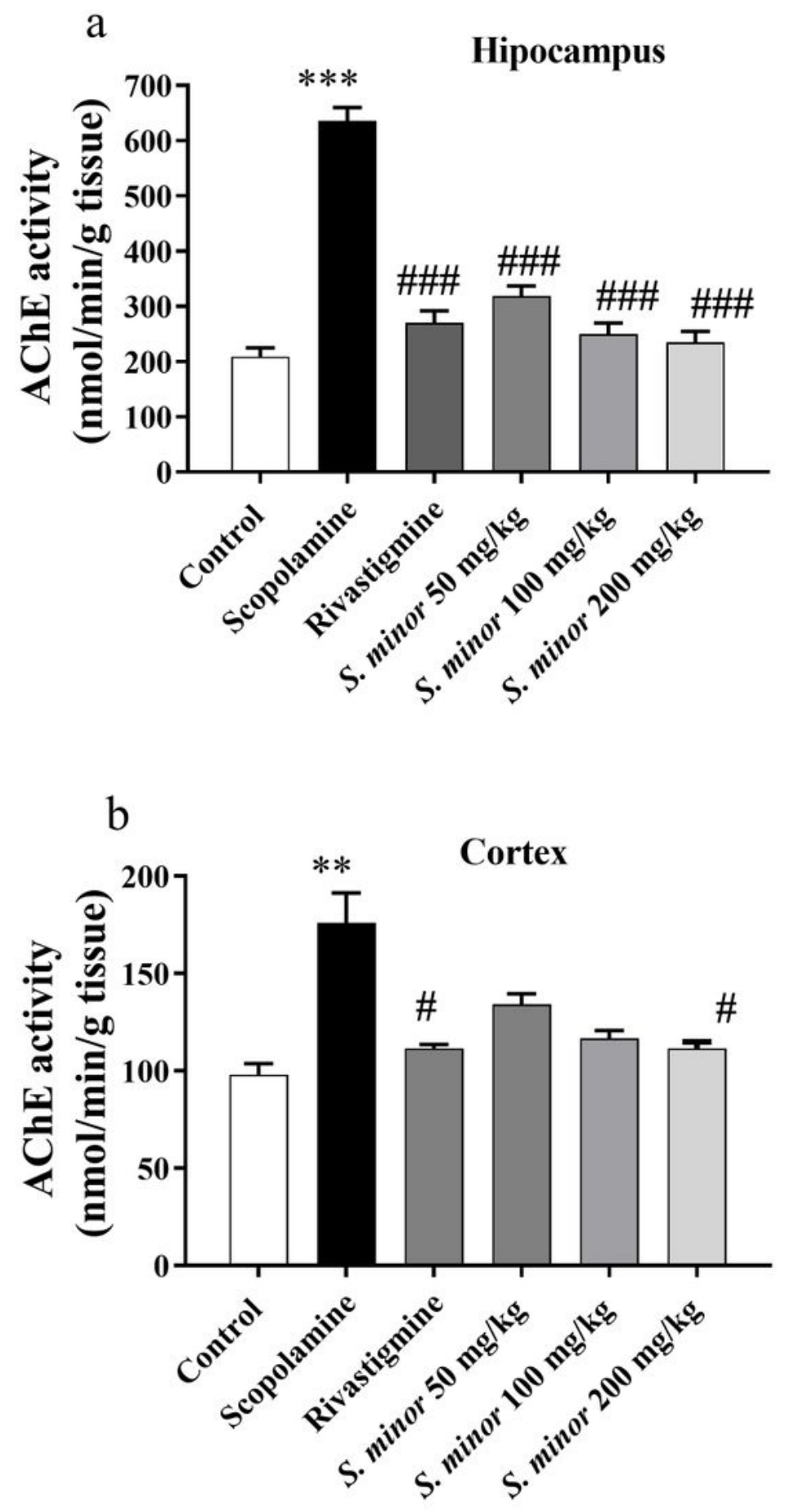

Figure 7

Effect of S. minor hydro-ethanolic extract on AChE in hipocampus (a) and cortex (b) of scopolaminetreated rats. Values were expressed as mean \pm SEM $(n=10) .{ }^{* \star} p<0.01,{ }^{* \star *} p<0.001$ Scopolamine group Vs. the control group; $\# \mathrm{P}<0.05$, \#\#\# $\mathrm{p}<0.001 \mathrm{~S}$. minor extract and rivastigmine Vs. Scopolamine group. 